\title{
Chronic stress and intestinal permeability: Lubiprostone regulates glucocorticoid receptor-mediated changes in colon epithelial tight junction proteins, barrier function, and visceral pain in the rodent and human
}

\author{
Ye Zong $^{1,2}$ | Shengtao Zhu ${ }^{1,2}$ | Shutian Zhang ${ }^{1}$ Gen Zheng ${ }^{2}$ | John W Wiley ${ }^{2}$ | \\ Shuangsong Hong ${ }^{2}$ iD
}

${ }^{1}$ Department of Gastroenterology, Beijing Friendship Hospital, Capital Medical University, Beijing, China

${ }^{2}$ Department of Internal

Medicine, University of Michigan, Ann Arbor, Michigan

\section{Correspondence}

Shuangsong Hong, Department of Internal Medicine, University of Michigan, Ann Arbor, MI.

Email: hongss@med.umich.edu

Funding information

National Center for Complementary and Alternative Medicine, Grant/Award Number: AT009253; National Institute of Diabetes and Digestive and Kidney Diseases, Grant/ Award Number: DK098205 and DK34933; University of Michigan, Grant/Award Number: P30 DK34933

\begin{abstract}
Background: Chronic psychological stress is associated with increased intestinal epithelial permeability and visceral hyperalgesia. Lubiprostone, an agonist for chloride channel-2, promotes secretion and accelerates restoration of injury-induced epithelial barrier dysfunction. The mechanisms underlying how lubiprostone regulates colon epithelial barrier function and visceral hyperalgesia in chronic stress remain unknown.

Methods: Male rats were subjected to water avoidance stress for 10 consecutive days. Lubiprostone was administered daily during the stress phase. Visceromotor response to colorectal distension was measured. Human colon crypts and cell lines were treated with cortisol and lubiprostone. The transepithelial electrical resistance and FITC-dextran permeability were assayed. Chromatin immunoprecipitation was conducted to assess glucocorticoid receptor binding at tight junction gene promoters.

Key Results: Lubiprostone significantly decreased chronic stress-induced visceral hyperalgesia in the rat $(P<0.05 ; n=6)$. WA stress decreased occludin and claudin-1 and increased claudin-2 in rat colon crypts, which was prevented by lubiprostone. Cortisol treatment induced similar alterations of tight junction protein expression in Caco-2/ BBE cells $(P<0.05)$ and significantly changed paracellular permeability in monolayers $(P<0.01)$. These changes were blocked by lubiprostone. Glucocorticoid receptor and its binding at occludin promoter region were decreased in cortisol-treated cells and human colon crypts, which was largely reversed by lubiprostone. In rat colonic cells, glucocorticoid receptor and its co-chaperone proteins were down-regulated after corticosterone treatment and lubiprostone reversed these changes.

Conclusions \& Inferences: Lubiprostone preferentially prevents chronic stress-induced alterations of intestinal epithelial tight junctions, barrier function, and visceral hyperalgesia that was associated with modulation of glucocorticoid receptor expression and function.
\end{abstract}

Abbreviations: ChIP, chromatin immunoprecipitation; CIC-2, chloride channel type 2; CRD, colorectal distention; EMG, electromyography; FITC, fluorescein isothiocyanate; FKBP5, FK506 binding protein 5; GR, glucocorticoid receptor; GRE, glucocorticoid response elements; Hsp, heat-shock protein; IBS, irritable bowel syndrome; Lub, lubiprostone; MR, mineralocorticoid receptor; TEER, transepithelial electrical resistance; VMR, visceral motor response; WA, water avoidance; ZO-1, zonula occludens-1. 
KEYWORDS

chronic stress; visceral hyperalgesia, glucocorticoid receptor, intestinal permeability,

lubiprostone, tight junction

\section{$1 \mid$ INTRODUCTION}

Irritable bowel syndrome (IBS) is a common functional gastrointestinal disorder characterized by abdominal discomfort or pain and changes in bowel habit. ${ }^{1-3}$ Increasing evidence suggests that disturbance of the intestinal epithelial barrier function contributes to diarrhea-prone IBS-related symptoms. ${ }^{4,5}$ For example, the enhanced paracellular permeability is positively correlated with abdominal pain in IBS patients. ${ }^{6}$ Recently, enhanced stress effects on gut barrier function have been implicated as a potential mechanism contributing to the pathophysiology of IBS. ${ }^{7,8}$ Chronic stress has significant effects on gut physiology and pathophysiology including alterations in gastrointestinal motility, enhanced visceral pain perception (hyperalgesia), and impaired intestinal barrier function in animal models ${ }^{9,10}$ and IBS patients. ${ }^{11,12}$

The corticoid receptor is one of the major players in mediating many physiological events in response to acute and chronic stress. ${ }^{13,14}$ The glucocorticoid receptor (GR), a ligand-activated transcription factor, depends on molecular chaperones for in vivo function. ${ }^{15}$ After ligand binding, GR is translocated to the nucleus and binds to DNA on glucocorticoid response elements (GREs), recruiting transcriptional machinery and various coactivators and corepressors to positively or negatively regulate gene transcription. GR translocation is mediated by the co-chaperone protein FK506 binding protein 5 (FKBP5) which is associated with the chaperone heat-shock protein 90 (Hsp90) to form a chaperon complex. ${ }^{16,17}$ The Hsp90-GR complex, in its ATP-bound form, is stabilized by cochaperone p23, whereas heat-shock protein 70 (Hsp70) mediates GR complex assembly and activity. ${ }^{15,18}$ The importance of these chaperones has been established in the pathogenesis and therapy of stress and mental disorders. ${ }^{14,17,19}$ In human colon epithelial cells, induction of Hsp70 expression displays a protective role in the epithelial barrier integrity which results in a decrease in paracellular permeability. ${ }^{20}$ The augmentation of heat-shock proteins and reduced barrier integrity has been reported in colon tissues in an acute stress animal model. ${ }^{21}$ The mechanism underlying how GR and its chaperones regulate intestinal paracellular permeability in chronic stress has not been determined.

Lubiprostone, a bicyclic fatty acid derived from prostaglandin E1 (PGE1), activates chloride channel type 2 (CIC-2) in the apical membrane of epithelial cells ${ }^{22}$ and promotes the passage of water into the luminal space and bowel movements which can improve symptoms associated with constipation. ${ }^{23,24} \mathrm{ClC}-2$ channel plays an important role in the modulation of tight junctions by influencing caveolar trafficking of the tight junction protein occludin. ${ }^{25}$ Targeted activation of CIC-2 chloride channels with lubiprostone stimulates repair of intestinal barrier function in the ischemia-injured porcine ileum

\section{Key Points}

- Chronic stress is associated with increased intestinal epithelial permeability and visceral hyperalgesia. Lubiprostone accelerates intestinal epithelial repair. It is unknown how lubiprostone regulates colon epithelial barrier function and visceral pain in chronic stress.

- Lubiprostone prevented chronic stress-induced differential alterations of epithelial tight junction proteins, down-regulation of glucocorticoid receptor and its chaperones, and increase in paracellular permeability and visceral pain in the rodent and human.

- Our findings support a novel mechanism for lubiprostone to regulate intestinal permeability and visceral pain.

and colon which is associated with impaired expression and function of tight junction proteins resulting in increased permeability. ${ }^{26}$ However, it is unknown whether lubiprostone has a preventative effect on the increased permeability and enhanced visceral pain in animal models of chronic stress. The goal of the present study was to examine the hypothesis that lubiprostone prevents GR-mediated disruption of colon epithelial tight junction proteins and prevents increase of paracellular permeability and visceral pain.

\section{2 | MATERIALS AND METHODS}

\subsection{Animals and water avoidance (WA) stress}

Male Sprague-Dawley rats (weighing 160-180 g) were obtained from Charles River Laboratories (Wilmington, MA, USA). Animals were housed in the animal facility that was maintained at $22^{\circ} \mathrm{C}$ with an automatic 12-hours light/dark cycle. The animals received a standard laboratory diet and tap water ad libitum. All experiments were approved by the University of Michigan Committee on Use and Care of Animals according to National Institutes of Health guidelines.

The animal study was conducted as shown in the following experimental scheme. Briefly, young-adult male rats were adapted in the animal facility for 3-5 days and then randomly grouped and subjected to 10 -day WA stress as described previously. ${ }^{27}$ The rats were placed on a glass platform in the middle of a tank filled with water $\left(22^{\circ} \mathrm{C}\right)$ to $1 \mathrm{~cm}$ below the height of the platform. The animals were maintained on the tank for 1 hour in the morning (8 AM-10 AM) daily for 10 consecutive days. Lubiprostone (Takeda Pharmaceutical North America, Deerfield, IL, USA) was delivered orally instead of gavage to rats, to 
avoid distress or irritation, twice daily with $500 \mu \mathrm{L}$ medium-chain triglycerides (MCT) as described. ${ }^{28}$ A dose of $10 \mu \mathrm{g} / \mathrm{kg}$ body weight was suggested by the manufacturer and proved effective by a serial dose response pre-experiments. Rats were weighed each day for determination of the amount of lubiprostone delivered. All animals were treated with lubiprostone prior to stress procedure each day for a period of 10 days during the WA stress phase (WA+Lub group). MCT, the delivery medium for lubiprostone, was administrated similarly to the SHAM control (MCT-CT) rats and WA stress (MCT-WA) rats. The MCT-CT rats were placed similarly for 1 hour daily for 10 days in a tank without water. The number of fecal output was recorded daily for each rat after 1 hour WA or SHAM stress. Behavioral assessments were conducted on the next day after completing the 10-day stress procedure. Separate groups of animals without behavioral measurements were used to harvest colon crypts from the distal colon, the same segment for balloon distention and visceral pain measurement. The aliquots of isolated colon crypts were used for biochemical and molecular characterization. The experimenter was blinded to animal treatment during behavioral experiments.

\subsection{Cell culture and treatment}

The Caco-2/BBE colonic epithelial cell line, originally derived from a human adenocarcinoma, was obtained from Prof. David E Smith (University of Michigan, Ann Arbor, MI, USA). Cells were maintained at $50 \%$ density in DMEM containing $25 \mathrm{mmol} / \mathrm{L}$ glucose, $3.7 \mathrm{~g} / \mathrm{L} \mathrm{NaHCO}_{3}, 4 \mathrm{mmol} / \mathrm{L}$ L-glutamine, $1 \%$ nonessential amino acids, $100 \mathrm{U} / \mathrm{L}$ penicillin/streptomycin (complete medium), supplemented with $10 \%$ heat-inactivated FBS (Sigma-Aldrich, St Louis, $\mathrm{MO}, \mathrm{USA}$ ) at $37^{\circ} \mathrm{C}$ in $10 \% \mathrm{CO}_{2}$. For differentiation, cells were seeded on Transwell filters, $12 \mathrm{~mm}$ diameter, $0.4 \mu \mathrm{m}$ pore diameter (Corning Inc, Lowell, MA, USA) at a density of $3.5 \times 10^{5} \mathrm{cells} / \mathrm{cm}^{2}$ in complete medium for two days to allow the formation of a confluent cell monolayer. From day 3 after seeding, cells were kept in the same medium in both compartments (10\% FBS Symmetric) and allowed to differentiate for 21 days with regular medium changes three times a week. ${ }^{30}$

Rat colon epithelial FRC/TEX cell lines used in this study was a generous gift from Dr Kimberly Rieger-Christ, Sophia Gordon

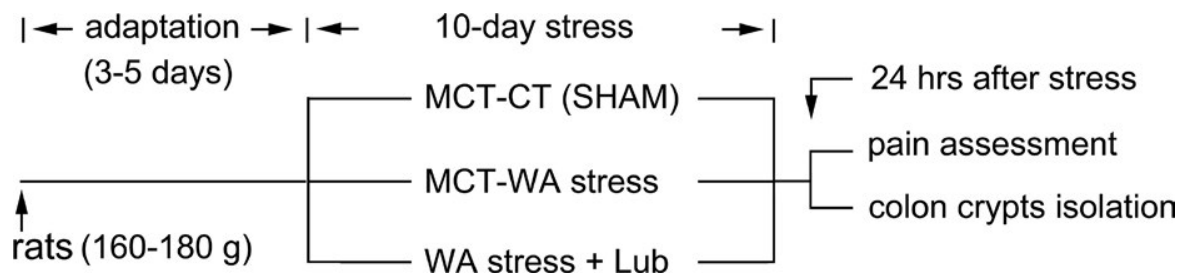

\section{2 | Visceral motor response (VMR) to colorectal distention (CRD)}

Visceral pain measurement was conducted as previously described. ${ }^{27,29}$ Briefly, rats were deeply anesthetized with subcutaneous injection of a mixture of ketamine $(60 \mathrm{mg} / \mathrm{kg})$ and xylazine ( $5 \mathrm{mg} / \mathrm{kg}$ ). An incision was made in the skin of the lower abdomen, and two perfluoroalkoxy-coated, 32-gauge stainless steel wires were inserted into the external oblique pelvic muscles superior to the inguinal ligament. Animals were injected with $500 \mu \mathrm{L}$ of $0.9 \%$ saline, and artificial tears eye ointment was placed onto their eyes. The animals were then allowed to recover for 3-5 days prior to the VMR measurement.

Measurement of the VMR to CRD was conducted in awake animals on day 11, next day after the completion of 10-day WA stress procedure. The VMR was quantified by measuring activity of electromyography (EMG) in the external oblique musculature in the awake animals. CRD was conducted to constant pressures of 10 , 20,40 , and $60 \mathrm{~mm} \mathrm{Hg}$ by a custom-made distension control device. The responses were considered stable if there was $<20 \%$ variability between 2 consecutive trials of CRD at $60 \mathrm{~mm} \mathrm{Hg}$. The increase in the area under curve (AUC), which is the sum of all recorded data points multiplied by the sample interval (in seconds) after baseline subtraction, was presented as the overall response during the course of the CRD test.
Cancer Center, Burlington, MA. These cells consist of two mycoplasma-negative rat colonic epithelial cell lines and the immortalized non-tumorigenic cell line. ${ }^{31}$ The derivative transformed FRC/ TEX cells were cultured in Dulbecco's modified Eagle's medium (DMEM) supplemented with $10 \%$ fetal bovine serum (FBS), hydrocortisone $(0.02 \mu \mathrm{g} / \mathrm{mL})$, insulin $(0.25 \mu \mathrm{g} / \mathrm{mL})$, transferrin $(0.12 \mu \mathrm{g} /$ $\mathrm{mL})$, glucose $(67.5 \mu \mathrm{g} / \mathrm{mL})$, and penicillin-streptomycin $(50 \mathrm{U} / \mathrm{mL})$ in a humidified environment at $37^{\circ} \mathrm{C}$ in the presence of $10 \% \mathrm{CO}_{2} \cdot{ }^{32}$ For treatment, FRC/TEX and Caco-2/BBE Cells were incubated with GR agonist corticosterone $(500 \mathrm{nmol} / \mathrm{L})$ for 24 hours with/without lubiprostone $(100 \mathrm{nmol} / \mathrm{L}$; dissolved in DMSO). DMSO at the final $0.01 \%(\mathrm{v} / \mathrm{v})$ concentration was used as the vehicle control. The cortisol dose at $500 \mathrm{nM}$ was determined to mimic the serum level in the stressed rats after 10-day chronic WA stress as described previously. ${ }^{9}$ Treated cells were then harvested for immunofluorescence staining and Western blot analysis.

\subsection{Human colon crypts culture and treatment}

Human colon crypts culture was conducted as described previously. ${ }^{33}$ Briefly, colon biopsies were collected from healthy control patients in cold Dulbecco's minimal essential medium (Life Technologies, Carlsbad, CA, USA), supplemented with $2 \mathrm{mmol} / \mathrm{L}$ GlutaMax (Life Technologies), $50 \mu \mathrm{g} / \mathrm{mL}$ gentamicin (Life Technologies), $100 \mu \mathrm{g} / \mathrm{mL}$ 
normocin (InvivoGen, San Diego, CA, USA), and $2.5 \mu \mathrm{g} / \mathrm{mL}$ amphotericin (Life Technologies) at the University of Michigan Hospitals according to the procedures approved by the Institutional Review Board (IRB). The mucosa/submucosa was surgically separated from the muscularis propria and incubated in Dulbecco's phosphate-buffered saline (DPBS; Life Technologies) supplemented with the above antimicrobials for 15 minutes. The tissues were then incubated in $10 \mathrm{mmol} / \mathrm{L}$ dithiothreitol (DTT; Sigma-Aldrich) for 15 minutes, followed by treatment with $8 \mathrm{mmol} / \mathrm{L}$ ethylenediaminetetraacetic acid (EDTA; Sigma-Aldrich) for 75 minutes. Crypts were isolated and washed with cold keratinocyte growth medium gold (KGMG) and cultured in KGMG with Matrigel (BD Biosciences, San Jose, CA, USA) at a crypt density of 50-75 crypts $/ 50 \mu \mathrm{L}$ Matrigel $/ 2 \mathrm{~cm}^{2}$ well. After cultured for 3 hours, crypts were treated with cortisol $(500 \mathrm{nmol} / \mathrm{L})$ with/without lubiprostone (100 nmol/L) for 24 hours. DMSO $(0.01 \%$ v/v) was used as the vehicle control.

\section{5 | Measurement of transepithelial electrical resistance (TEER) and FITC-Dextran permeability}

The TEER assay was used to measure the effect of treatments on the integrity of the tight junctions between Caco-2/BBE cells as a model of human intestinal epithelium. Caco-2/BBE cells were seeded on 24well 12-mm polyester Transwell filters (Corning, Corning, NY, USA) with $0.4 \mu \mathrm{m}$ pore size at a concentration of $2 \times 10^{5}$ cells/Transwell. Cells were grown in DMEM supplemented with $0.01 \mathrm{mg} / \mathrm{mL}$ human transferrin, 10\% FBS, and pen/strep for 21 days until they formed a differentiated monolayer. For treatment, cortisol $(500 \mathrm{nmol} / \mathrm{L})$ was added to the apical site (upper chamber) of the transwell cultures since the expression of GR receptors is dominant at the apical epithelial cells in human colon crypts. ${ }^{34}$ To determine the effect of cortisol, the TEER was measured before and after cortisol treatment for 24 hours in the presence and absence of lubiprostone $(100 \mathrm{~nm}$; inner/upper chamber) or DMSO (0.01\% v/v) vehicle using an EVOM2 epithelial voltage meter (World Precision Instruments, Sarasota, FL, USA). After washing the cells, DMEM was dispensed into each filter in the apical and basolateral chamber; electrical probes were then immersed in the apical and basolateral chambers to measure the resistance of the monolayer. TEER was calculated after subtraction of the intrinsic resistance of the cell-free filter. To measure dextran permeability, fluorescein isothiocyanate (FITC)-dextran (4 kDa; $3 \mathrm{mg} / \mathrm{mL}$ ) was added to the upper chamber without medium change. Aliquots were withdrawn from the lower chambers after 4 hours and assayed for fluorescence at $515 \mathrm{~nm}$ with excitation at $492 \mathrm{~nm}$.

\subsection{Western blot analysis}

Colon tissues in rats that had not undergone surgery or visceral pain measurement were dissected out next day after completing the 10-day WA stress procedure. The dissected colon segments were reversed inside-out and washed with $2 \mathrm{mmol} / \mathrm{L}$ DTT in cold PBS. Then, tissues were incubated with $4 \mathrm{mmol} / \mathrm{L}$ EDTA in cold PBS for 5 minutes with shaking. The epithelium layers were gently scrapped off with a forceps and collected in PBS, followed by centrifugation at $500 \mathrm{~g}$ for 5 minutes. The crypts aliquots containing epithelium were stored at $-80^{\circ} \mathrm{C}$ for later use or immediately homogenized in ice-cold lysis buffer containing $50 \mathrm{mmol} / \mathrm{L}$ Tris, $\mathrm{pH} 8.0,150 \mathrm{mmol} / \mathrm{L}$ $\mathrm{NaCl}, 1 \mathrm{mmol} / \mathrm{L}$ EGTA, $50 \mathrm{mmol} / \mathrm{L} \mathrm{NaF}, 1.5 \mathrm{mmol} / \mathrm{L} \mathrm{MgCl}_{2}, 10 \%$ $\mathrm{v} / \mathrm{v}$ glycerol, $1 \% \mathrm{v} / \mathrm{v}$ Triton $\mathrm{X}-100,1 \mathrm{mmol} / \mathrm{L}$ phenylmethylsulfonyl fluoride, $1 \mathrm{mmol} / \mathrm{L} \mathrm{Na}_{3} \mathrm{VO}_{4}$, and Complete Protease Inhibitor cocktail (Roche Diagnostics, Indianapolis, IN, USA). In separate studies, rat FRC/TEX and human Caco-2/BBE cells were collected and homogenized using the same lysis buffer. Proteins were separated and transblotted to polyvinylidene difluoride membranes (Bio-Rad, Hercules, CA, USA). The membranes were blocked and incubated with primary antibodies for GR (Cell Signaling, Danvers, MA, USA), mineralocorticoid receptor (MR; Santa Cruz Biotechnology, Santa Cruz, CA, USA), FKPB5 (Cell Signaling), Hsp90 (Cell Signaling); Hsp70 (Cayman Chemical, Ann Arbor, MI, USA), Hsp23 (p23; Cayman Chemical), claudin-1 \& claudin-2 (Invitrogen Corp., Camarillo, CA, USA), occludin (Abcam, Cambridge, MA, USA), and -actin (Sigma-Aldrich) at $4^{\circ} \mathrm{C}$, overnight, and subsequently with secondary antibodies (1:5000; Cell Signaling) for 1 hour at room temperature. The X-ray films were developed using SuperSignal West Dura Chemiluminescent Substrate Kit (Thermo Fisher Scientific, Rockford, IL, USA).

\subsection{Quantitative PCR (qPCR)}

Total RNA from rat colon crypt aliquots was isolated using the Trizol (Life Technologies, Grand Island, NY, USA) and RNeasy kit (Qiagen, Hilden, Germany). qPCR was performed using the BioRad iScript One-Step Reverse-Transcription PCR Kit with SYBR Green (Bio-Rad, Hercules, CA, USA) using the following specific primers from Integrated DNA Technologies (Coralville, IA, USA): claudin-1: forward-ATGACCCCTATCAATGCCAG, reverse-TGGTG TTGGGTAAGAGGTTG; claudin-2: forward-CAGCTCCGTTTTCTA GATGCC, reverse-TGCGGCTCTTGTTTCTTGGA; occludin: forwardAAAGCAGGGAAGGCGAAG, reverse-TGTTGATCTGAAGTGATAGG TGG; GR: forward-GCGTCAAGTGATTGCAGCAGTGAA, reverseGCAAAGCAGAGCAGGTTTCCACTT; GAPDH: forward-TGTGAACG GATTTGGCCGTA, reverse-TGAACTTGCCGTGGGTAGAG.

\section{8 | Chromatin Immunoprecipitation (ChIP)}

Chromatin immunoprecipitation was performed using a chromatin immunoprecipitation kit (EMD Millipore, Billerica, MA, USA). Briefly, the colon crypt aliquots or Caco-2/BBE cells were cross-linked using $1 \%$ formaldehyde and terminated by incubation with $0.125 \mathrm{~mol} / \mathrm{L}$ glycine for 5 minutes. The cell lysate was incubated for 10 minutes at $4^{\circ} \mathrm{C}$, and the crude nuclear extract was collected by centrifugation at $600 \times \mathrm{g}$ for 5 minutes at $4^{\circ} \mathrm{C}$. The DNA was sonicated to random fragments between $200 \mathrm{bp}$ and $500 \mathrm{bp}$. The chromatin was subjected to immunoprecipitation using the following antibodies: GR(\#3660; Cell Signaling Technology, Danvers, MA, USA). Normal rabbit IgG was used as the control. DNA was eluted in elution buffer and used for PCR amplification. Primers 
for rat occludin promoter (forward-CATTTAATCAAACCTGGCAGC, reverse-CCTGGAGCTAGCAGAGTTAAAAGG) and for human occludin promoter (forward-CGACACACCACACCTACACT, reverseATGCGCACCAACGTGGAA) were obtained from Life Technologies (Grand Island, NY, USA). PCR was performed using Bio-Rad iScript ${ }^{\mathrm{TM}}$ One-Step RT-PCR Kit with SYBR® Green (Bio-Rad, Hercules, CA, USA).

\section{9 | Immunofluorescence}

FRC/TEX cells cultured on cover glasses were fixed for 30 minutes in $4 \%$ paraformaldehyde in $0.1 \mathrm{~mol} / \mathrm{L}$ phosphate buffer. Cells were then permeabilized with $0.3 \%$ Triton $\mathrm{X}-100$ for 1 hour and then blocked with $10 \%$ normal goat serum in PBS with $0.3 \%$ Triton X-100 for 4 hours at room temperature. Primary antibodies used for overnight incubation were anti-occludin (1:1000) and anti-ZO1 (1:5000). Secondary antibodies Alexa Fluor 488 (1:500) and Alexa Fluor 594 (1:500) from Molecular Probes (Life Technologies) were used for incubation for 2 hour.

\subsection{0 | Statistical analysis}

To examine the VMR in response to CRD pressures, the EMG amplitudes, represented by calculating the AUC, were normalized as percentage of baseline response for the highest pressure $(60 \mathrm{~mm} \mathrm{Hg})$ for each rat and then averaged for each group of rats. The effects of stress and/or lubiprostone treatment on the VMR to CRD were analyzed using a repeated-measures two-way ANOVA followed by Bonferroni posttest comparisons. Unpaired Student's $t$ test was used to examine the data for protein, TEER, FITC-dextran, and ChIP assays. Results were expressed as means \pm SEM $P<0.05$ was considered statistically significant.

\section{3 | RESULTS}

\section{1 | Lubiprostone prevented chronic stress-induced visceral hyperalgesia in the rat}

In our previous studies, we demonstrated that chronic WA stress induced visceral hyperalgesia which was largely blocked by GR receptor antagonist RU-486. ${ }^{27,35}$ It is unknown whether lubiprostone will have a preventative effect on chronic stress-associated visceral pain perception. In this study, we measured body weight gain, fecal pellet output and visceral pain in WA-stressed rats treated with lubiprostone or MCT vehicle. Intermittent 10-day WA stress induced a significant reduction in body weight gain in MCT-WA stress rats $(29.0 \pm 2.2 \mathrm{~g})$ during this 10-day stress period compared to MCT-CT rats $(43.5 \pm 2.8 \mathrm{~g})$ as shown in Figure 1A $(P<0.001 ; n=6-8)$. Lubiprostone treatment prevented stress-induced reduction in body weight gain. The average number of fecal pellet output during 1-hour stress each day was $0.78 \pm 0.19$ in MCT-CT rats, and it significantly increased to $4.1 \pm 0.3$ in MCT-WA rats $(P<0.001)$. Lubiprostone treatment did not affect the fecal pellet output compared to MCT-WA rats (Figure 1B). In MCT-WA rats, VMR in response to CRD, expressed as EMG activity, increased significantly
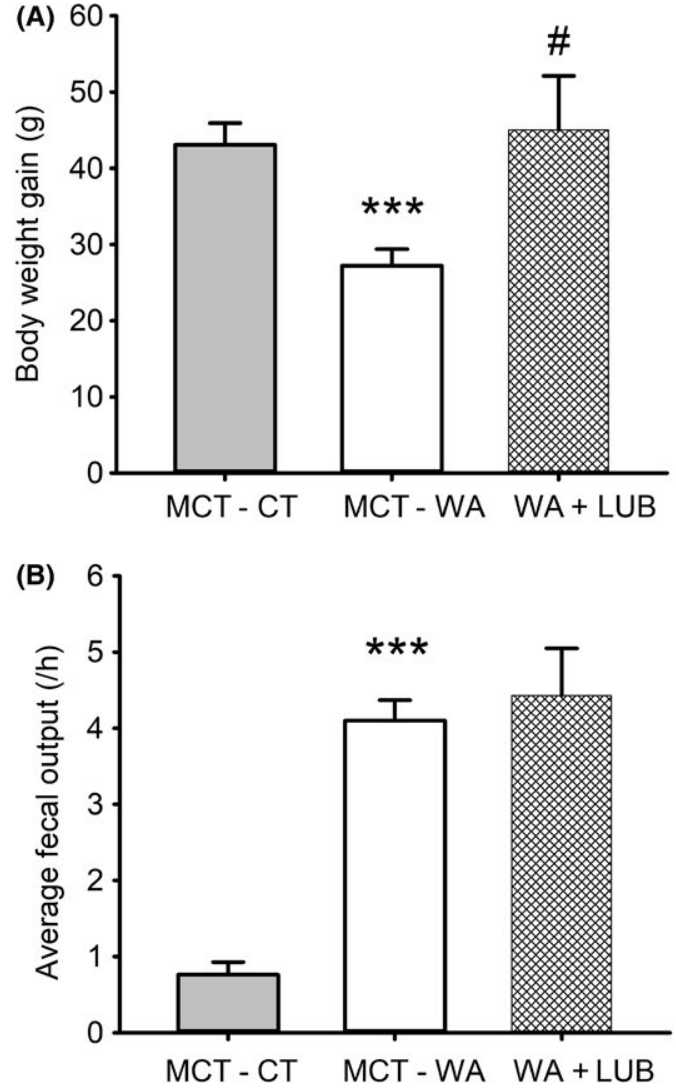

(C)

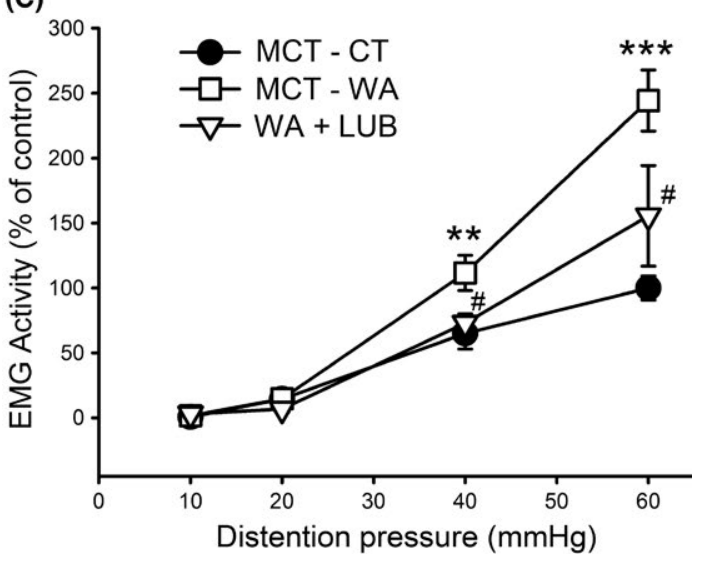

FIGURE 1 Effect of lubiprostone (Lub) on chronic WA stressinduced visceral hyperalgesia in the rat. A, Body weight gain after 10-day WA or SHAM stress in rats treated with lubiprostone or MCT vehicle. $\mathrm{B}$, Averaged number of fecal pellet output during 1 hour WA or SHAM stress period in MCT-CT, MCT-WA, and WA+Lub rat group. C, EMG amplitude, expressed as AUC of the VMR to CRD, was significantly increased following 10-day WA stress compared with the controls. Lubiprostone treatment largely prevented WA stressinduced increase in VMR to CRD at 40 and $60 \mathrm{~mm} \mathrm{Hg}$ pressures. Data are expressed as mean \pm SEM, $n=6$-8 in each group. ${ }^{* *} P<0.01$; ${ }^{* * *} P<0.001$ for MCT-WA rats compared to the MCT-CT rats. $\# P<0.05$ for lubiprostone-treated stressed rats (WA+Lub) compared to MCT-WA rats without lubiprostone treatment.

with the quantitative PCR result for claudin-1, lubiprostone had a modest reversal effect on chronic stress-induced down-regulation of claudin-1. 


\section{3 | Effects of lubiprostone on cortisol-induced changes in tight junctions in human colon crypts and Caco-2/BBE cells}

To test whether disruption of tight junctions observed in chronically stressed rats can be reproduced in human cells, differentiated Caco-2/ BBE cells and human colon crypts derived from healthy controls were treated with cortisol. The optimal dose for cortisol treatment was determined by treating cells with serial concentrations of cortisol for 24 hours. As shown in Figure 3A, occludin protein decreased in a dosedependent manner in these cells after cortisol treatment and the dose of $500 \mathrm{nmol} / \mathrm{L}$ cortisol was used for the subsequent experiments. As shown in Figure 3B,C, cortisol treatment induced 53.8\% $\pm 7.5 \%$ decrease in claudin-1 $(P<0.05), 45.5 \% \pm 9.4 \%$ decrease in occludin $(P<0.05)$, and $171.3 \% \pm 24.3 \%$ increase in claudin-2 $(P<0.01)$ compared with the control groups, respectively, in differentiated Caco-2/BBE cells after cortisol treatment. Lubiprostone significantly prevented these changes caused by cortisol. The protein levels of claudin-1, occludin, and claudin-2 were $125.5 \% \pm 9.3 \%, 92.0 \% \pm 5.3 \%$, and $191.3 \% \pm 32.9 \%$, respectively, in cortisol-treated cells in the presence of lubiprostone compared to their corresponding control levels. The differences between cortisol-treated cells with and without lubiprostone were significant $(P<0.05)$. As shown in Figure 3D,E, human colon crypts demonstrated $55.7 \% \pm 4.4 \%$ decrease in claudin $-1(P<0.01), 33.7 \% \pm 9.9 \%$ decrease in occludin $(P<0.05)$, and $70.7 \% \pm 13.5 \%$ increase in claudin-2 $(P<0.01)$, respectively, after cortisol treatment compared with the control groups. Co-treatment with lubiprostone significantly prevented the decreases of claudin-1 and occludin and the increase of claudin-2. The levels of claudin-1, occludin, and claudin-2 in lubiprostone and cortisol treated were $73.8 \% \pm 13.1 \%, 81.4 \% \pm 7.04 \%$, and $147.1 \% \pm 8.6 \%$ of their corresponding control levels, respectively $(P<0.05)$.

\subsection{Effects of lubiprostone on paracellular permeability in Caco-2/BBE cells}

In differentiated Caco-2/BBE cell monolayers, TEER was measured before and after treatment with cortisol in the presence and absence of lubiprostone, while FITC-dextran leakiness was measured after cortisol treatment with/without lubiprostone. As shown in Figure 4A, change of TEER decreased $24.9 \pm 5.9 \mathrm{ohms} / \mathrm{cm}^{2}$ in Caco-2/BBE monolayers after cortisol treatment for 24 hours, whereas it increased $14.8 \pm 7.1 \mathrm{ohms} / \mathrm{cm}^{2}$ in the vehicle controls. The difference between these two groups was significant $(P<0.01 ; \mathrm{n}=18)$. In the presence of lubiprostone, change of TEER increased $28.4 \pm 9.4 \mathrm{ohms} / \mathrm{cm}^{2}$ in cortisol-treated cells, which was significantly different compared to those without lubiprostone co-treatment $(P<0.001 ; \mathrm{n}=18)$. Moreover, FITC-dextran measurement in the differentiated Caco-2/BBE monolayers showed $40.7 \% \pm 2.5 \%$ increase in the intensity of $4 \mathrm{kDa}$ FITC-dextran in the lower chamber of the Transwell cell cultures compared to the controls $(P<0.01 ; \mathrm{n}=12)$. This enhancement was reduced significantly to $122.7 \% \pm 4.8 \%$ of the control by treatment with lubiprostone $(P<0.01$; Figure 4B).
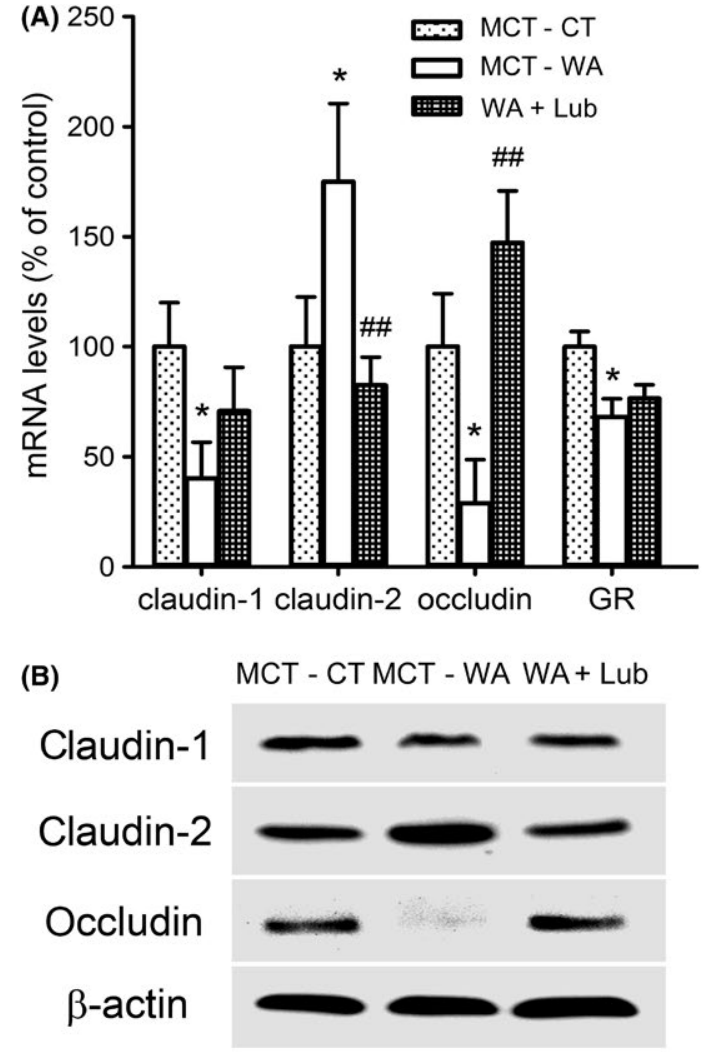

(C)

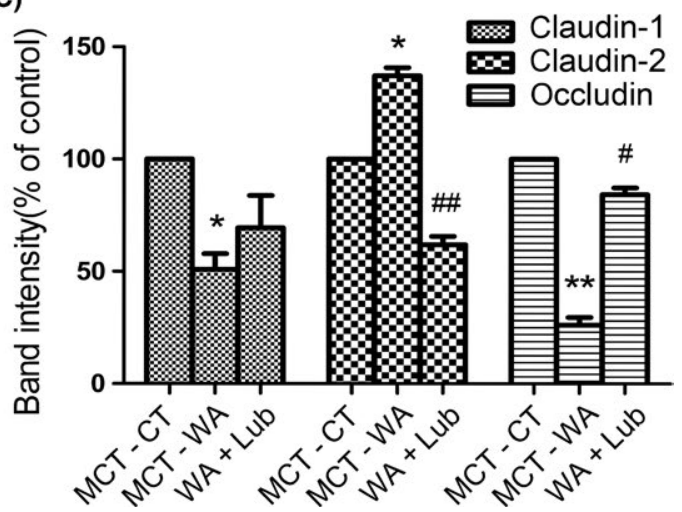

FIGURE 2 Lubiprostone treatment differentially altered epithelial tight junction protein expression in the rat colon in chronic stress. A, Quantitative PCR analysis of the expression levels of tight junction genes including claudin-1, claudin-2, and occludin and the expression of GR receptor in colon crypts of MCT-WA rats compared to MCT$\mathrm{CT}$ rats in the presence and absence of lubiprostone. B, Immunoblot for detection of claudin-1, claudin-2, and occludin proteins in the colon crypts in MCT-CT, MCT-WA, and WA+Lub rats. C, Bar graph depicting the relative protein levels of claudin-1, claudin-2, and occludin in WA+Lub rats compared to MCT-WA rats and MCT-CT rats. $\mathrm{n}=4-6$ of each group. ${ }^{*} \mathrm{P}<0.05$; ${ }^{* *} \mathrm{P}<0.01$ for MCT-WA rats compared to MCT-CT rats. \#P<0.05; \#\#P<0.01 for WA+Lub rats compared to MCT-WA rats without lubiprostone treatment.

\section{5 | Lubiprostone prevented cortisol-induced down-regulation of GR in human samples}

We reported previously that $G R$ was down-regulated after cortisol treatment in Caco-2/BBE cells. ${ }^{34}$ Here, we examined 


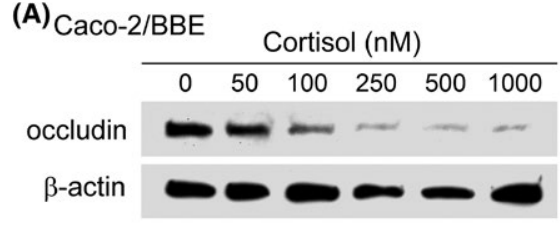

(B)

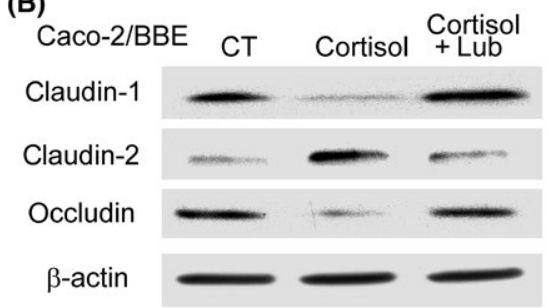

(C)

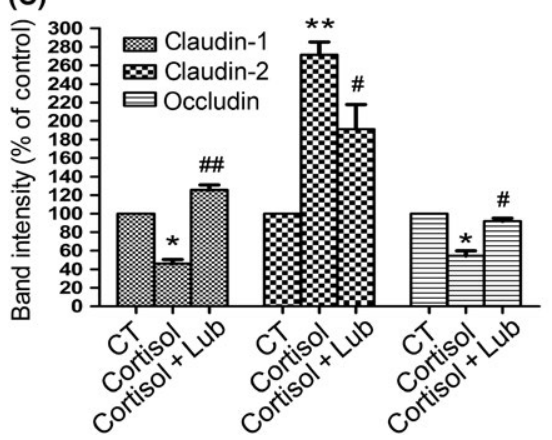

(D)

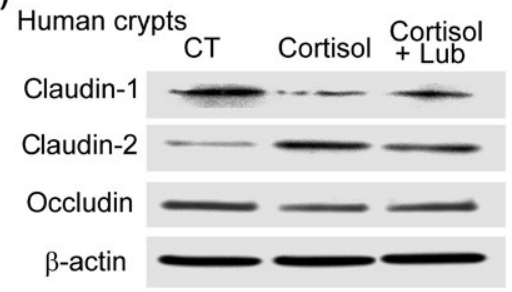

(E)

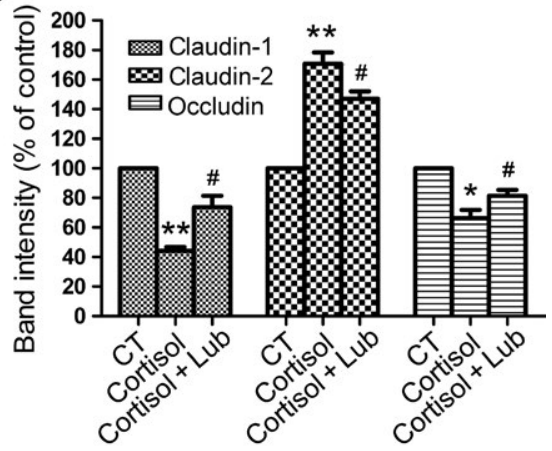

FIGURE 3 Differential effects of cortisol and lubiprostone on tight junction proteins in differentiated Caco-2/BBE cells and acutely harvested human colon crypts. A, Dose response effect of cortisol treatment (0-1000 nmol/L; 24 hours) on occludin expression in Caco-2/ BBE cells. B, Differential changes of claudin-1, claudin-2, and occludin in Caco-2/BBE cells treated by 500 nmol/L cortisol for 24 hours in the presence and absence of lubiprostone (100 nmol/L). C, Statistical analysis of tight junction protein levels in Caco-2/BBE cells after cortisol and lubiprostone treatment. D, Immunoblots for tight junction proteins in acutely harvested colon crypts from healthy control patients after treatment with cortisol $(500 \mathrm{nmol} / \mathrm{L})$ and/or lubiprostone $(100 \mathrm{nmol} / \mathrm{L})$ for 24 hours. E, Statistical analysis showed differential effects of cortisol on claudin-1, claudin-2 and occludin protein expression in human colon crypts with/without lubiprostone treatment. $\mathrm{n}=3-4$. ${ }^{*} P<0.05 ;{ }^{* *} P<0.01$ for cortisol treatment compared to the controls. \#P<0.05; \#\#P<0.01 for cortisol and lubiprostone-treated cells compared to the cortisol-treated cells.

whether lubiprostone treatment altered GR expression. As shown in Figure 5A, the protein level of GR in differentiated Caco-2/BBE cells was significantly decreased to $36.6 \% \pm 4.7 \%$ after cortisol treatment for 24 hours $(P<0.01)$. Administration of lubiprostone during cortisol treatment reversed GR expression to $52.6 \% \pm 7.5 \%$ of the untreated level $(P<0.05)$. Similarly, GR protein expression decreased $64.1 \% \pm 5.3 \%$ in acutely harvested human colon crypts after cortisol treatment for 24 hours $(P<0.01)$ as shown in Figure 5B. Lubiprostone significantly reversed $G R$ protein level to $113.5 \% \pm 10.9 \%$ of the untreated control $(P<0.01)$. In addition, we examined GR protein levels in colon crypts from rats subjected to 10-day WA stress with/without lubiprostone. As shown in Figure 5C, GR protein was significantly decreased in colon crypts in MCT-WA rats compared to MCT-CT rats $(P<0.001 ; n=5)$. Lubiprostone treatment partially reserved GR protein level (to $70.6 \% \pm 21.5 \%$ ) in WA+Lub group compared to the level of $40.1 \% \pm 14.4 \%$ in MCT-WA group. The difference between these two groups was not significant $(P=0.137 ; \mathrm{n}=5)$.

\subsection{Lubiprostone reversed cortisol-induced down- regulation of GR co-chaperones}

We examined GR chaperon proteins in differentiated Caco-2/BBE cells to test the hypothesis that GR function can be regulated by lubiprostone. As shown in Figure 6, both cortisol and lubiprostone did not alter the levels of GR chaperon proteins Hsp90 and Hsp70. In contrast, GR co-chaperon proteins $\mathrm{p} 23$ and FKBP5 were significantly decreased to $40.7 \% \pm 6.6 \%(P<0.01)$ and $79.8 \% \pm 10.5 \%(P<0.05)$ of the control levels, respectively, in Caco-2 cells treated by cortisol. Lubiprostone co-treatment significantly blocked cortisol-induced down-regulation of p23 and FKBP5, suggesting the regulatory effect of lubiprostone on GR expression and function.

\section{7 | Lubiprostone inhibited cortisol-induced decrease in GR binding to occludin gene promoter}

Next, we tested whether the binding of GR, as a positive transcription factor, to occludin promoter regions was affected by cortisol and 

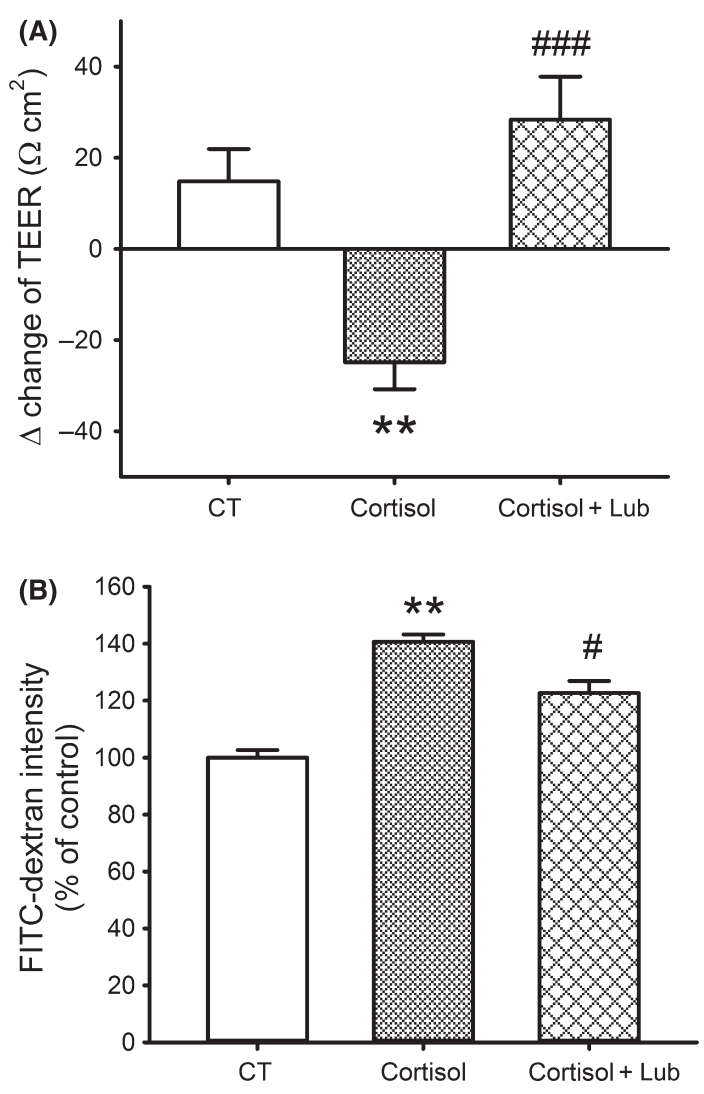

FIGURE 4 Paracellular permeability measurements in differentiated Caco-2/BBE monolayers in the presence and absence of cortisol and lubiprostone. A, The changes of transepithelial electrical resistance (TEER) before and after treatment with cortisol $(500 \mathrm{nmol} / \mathrm{L})$ and/or lubiprostone (100 nmol/L) for 24 hours in Caco-2/BBE cells cultured in Transwells for 21 days. $n=18$. (B) FITC-dextran ( $4 \mathrm{kDa}$ ) permeability measurement in 21-day cultured Caco-2/BBE cells after $500 \mathrm{nmol} / \mathrm{L}$ cortisol treatment for 24 hours in the presence and absence of lubiprostone ( $100 \mathrm{nmol} / \mathrm{L}) . \mathrm{n}=12 .{ }^{* *} \mathrm{P}<0.01$ for cortisol-treated cells compared to the controls. \#P $<0.05$; \#\#\#P $<0.001$ for cortisol and lubiprostone-treated cells compared to the cortisol-treated cells.

lubiprostone. As shown in Figure 7A, ChIP analysis revealed that the binding of GR protein to occludin gene promoter region was decreased in colon crypts in MCT-WA rats compared to MCT-CT rats. Treatment with lubiprostone during the stress phase prevented the decrease of GR binding to the occludin promoter, which is consistent with the effect of lubiprostone on chronic stress-induced down-regulation of occludin protein expression in the rat colon. In differentiated Caco-2/BBE cells, the relative amount of GR binding to occludin promoter decreased substantially treated by cortisol compared with controls. Lubiprostone treatment prevented the decrease of GR binding to the occludin promoter caused by cortisol administration as shown in Figure 7B.

\section{8 | Lubiprostone prevented corticosterone- induced alterations of GR chaperon protein in the rat colonic cells}

In rat colonic FRC/TEX cells, occludin expression and localization were significantly disrupted after corticosterone treatment and this change was prevented by lubiprostone treatment (Figure 8A). In contrast, ZO-1 expression and localization were not altered by cortisol treatment. As shown in Figure 8B, GR protein level was decreased in corticosterone-treated FRC/TEX cells which was largely reversed by lubiprostone, whereas MR was not affected by corticosterone. Corticosterone had no significant effect on GR chaperon protein Hsp90, but decreased protein levels of GR co-chaperon proteins p23 and FKBP5. Lubiprostone treatment normalized the down-regulation of p23 and FKBP5 in these cells.

\section{4 | DISCUSSION}

In this study, we revealed a novel role for lubiprostone to ameliorate stress-induced disruption of intestinal epithelial tight junction protein expression and function in the rodent and human colon that was associated with regulation of GR receptor expression and function. Our data demonstrate that lubiprostone prevents chronic WA stress-induced down-regulation of occludin and up-regulation of claudin-2 in rat colon crypts and significantly reduced visceral hyperalgesia observed in the stressed rats. Stress-induced alterations of claudin-1, claudin-2, and occludin were reproduced in Caco-2/ BBE cells and control human colon crypts treated with cortisol, an agonist for GR receptor. Lubiprostone blocked these changes and prevented cortisol-induced epithelial barrier dysfunction in Caco-2/ BBE monolayers. Furthermore, GR expression was decreased in cortisol-treated Caco-2/BBE cells and human colon crypts, which was largely reversed by lubiprostone. ChIP-qPCR assay revealed that lubiprostone normalized decreased GR binding at occludin promoter region under stress conditions. In addition, GR and its co-chaperone proteins p23 and FKBP5 were down-regulated after corticosterone treatment in rat colonic cells and lubiprostone prevented these changes.

Intestinal epithelial tight junction protein claudins have two different functional subcategories affecting paracellular permeability. One type of claudins, such as claudin-1, acts as "sealing" molecules which tighten the paracellular pathway against ions and larger solutes and maintain the integrity of the paracellular tight junctions with other tight junction proteins, that is, occludin. Disruption of these claudins and occludin expression decreases transepithelial electric resistance (TEER) and increases paracellular permeability. The other type of claudins, such as claudin-2, function as "pore-forming" molecules which enhance paracellular permeability in a charge-selective fashion. ${ }^{36,37}$ For example, claudin-1 contributes to maintaining a high TEER in cell culture models and is indispensable for creating and maintaining the epidermal barrier. ${ }^{38,39}$ In contrast, over-expression of claudin-2 induces lower transepithelial resistance in kidney cells and increases paracellular permeability. ${ }^{40,41}$ In our study, we observed that chronic WA stress induced the reduction in the protein levels of claudin-1 and occludin and increase in the protein level of claudin-2 in colonic epithelium in rats. This is consistent with our previous report that corticosterone induced down-regulation of tight junction proteins and increase in colon epithelial permeability 
FIGURE 5 Effects of lubiprostone on GR receptor protein expression in differentiated Caco-2/BBE cells, human colon crypts, and stressed rats. A, Protein expression of GR receptor in 21-day cultured Caco-2/BBE cells treated by cortisol (500 nmol/L) and lubiprostone (100 nmol/L) for 24 hours. B, Cortisol treatment (500 nmol/L; 24 hours) significantly decreased GR protein level in human colon crypts. Lubiprostone (100 nmol/L) prevented cortisol-induced down-regulation of GR receptor. C, GR protein expression in colon crypts isolated from MCT-CT, MCT-WA, and WA+Lub rat groups. $\mathrm{n}=3-5 .{ }^{* *} \mathrm{P}<0.01$ for cortisoltreated group compared to the controls. ${ }^{* * *} P<0.01$ for MCT-WA rats compared to $\mathrm{MCT}-\mathrm{CT}$ rats. $\# P<0.05$; \#\# $<0.01$ for cortisol and lubiprostone-treated group compared to the cortisol-treated group.

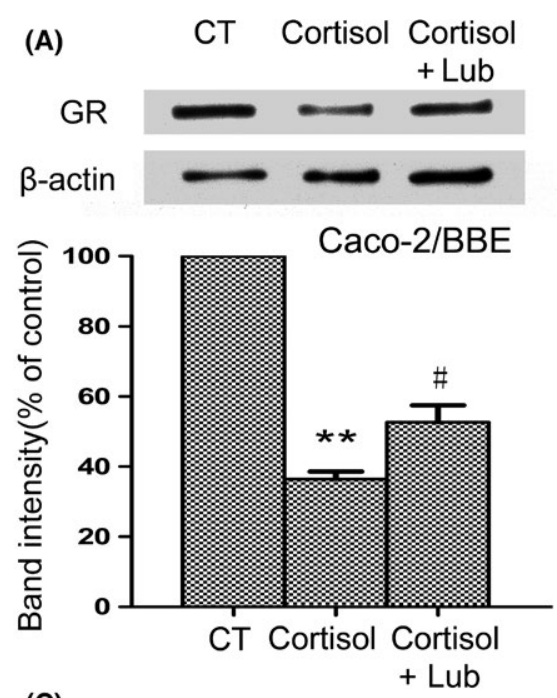

(B)

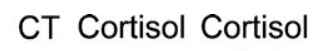

+ Lub
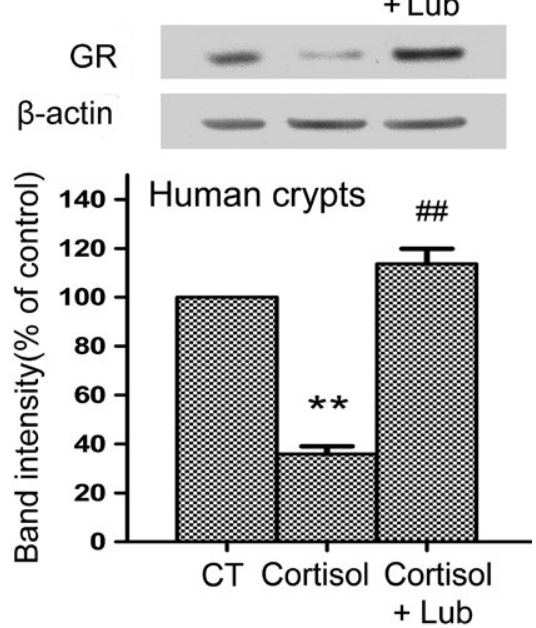

(C)

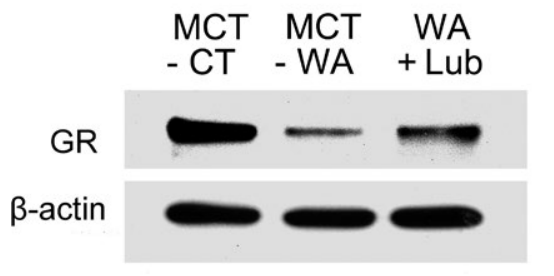

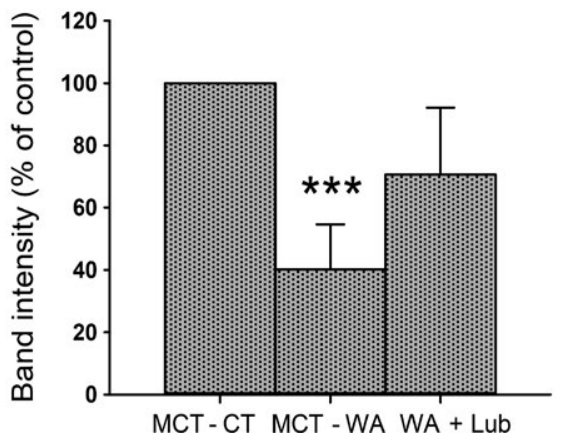
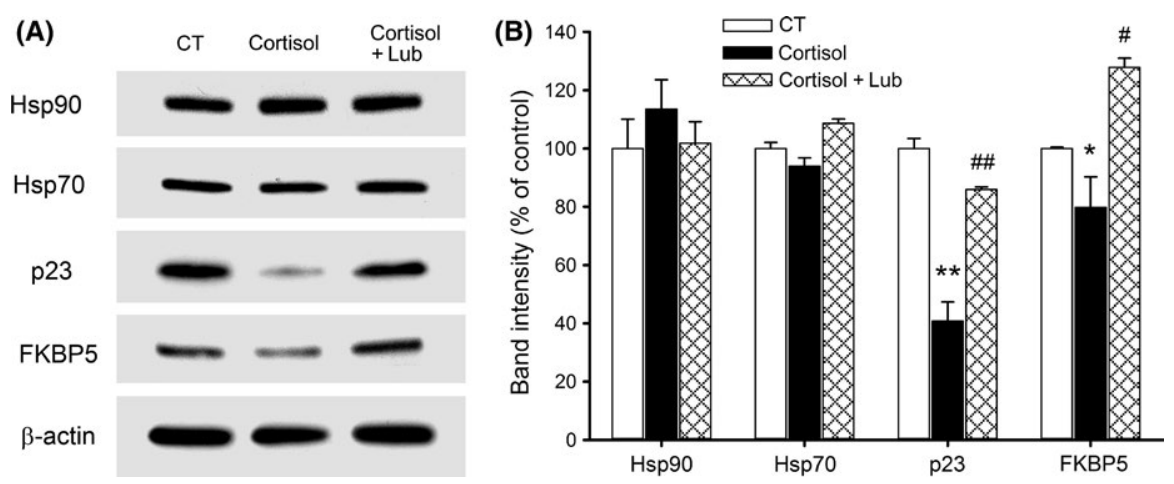

FIGURE 6 Differential effects of cortisol and lubiprostone on the alterations of GR chaperone proteins in differentiated Caco-2/BBE cells. A, Immunoblots for probing the express levels of GR chaperone and co-chaperone proteins including Hsp90, Hsp70, p23, and FKBP5 in 21-day cultured Caco-2/BBE cells in the presence and absence of cortisol ( $500 \mathrm{nmol} / \mathrm{L} ; 24$ hours) and lubiprostone (100 nmol/L; 24 hours). B, Statistical bar graph showed that cortisol treatment decreased p23 and FKBP5 in Caco-2/BBE cells and lubiprostone treatment largely blocked down-regulation of p23 and FKBP5 induced by cortisol. $\mathrm{n}=3 .{ }^{*} \mathrm{P}<0.05$; ${ }^{* *} \mathrm{P}<0.01$ for cortisol-treated cells compared to the controls. \#P < 0.05; \#\# < 0.01 for cortisol and lubiprostone-treated group compared to the cortisol-treated group.

in the rats ${ }^{9}$ and that chronic stress resulted in impairment of intestinal barrier function and visceral hyperalgesia. ${ }^{9,10}$ It has been reported that claudin-2, which is sensitive to stressful conditions, is involved in paracellular water transport and contributes $23 \%-30 \%$ of the total water transport in proximal kidney tubules. ${ }^{42,43}$ The expression of pore-forming claudin-2 could be induced by tumor necrosis factor-neuropeptide $Y$ "cross-talk" in vitro which was associated with increased epithelial permeability in inflammation. ${ }^{44}$ In normal colon, claudin-2 is highly expressed in the crypt bottom containing the undifferentiated and proliferative colonocytes. ${ }^{45}$ However, the detailed function of claudin-2 in the colon is largely unknown, particularly under chronic stress conditions. We hypothesize that chronic stress-induced up-regulation of claudin- 2 in the colon can lead to increased water secretion and epithelial permeability and that prevention of claudin- 2 increase by lubiprostone can normalize chronic stress-induced disruption of intestinal barrier function. It has been 
(A)

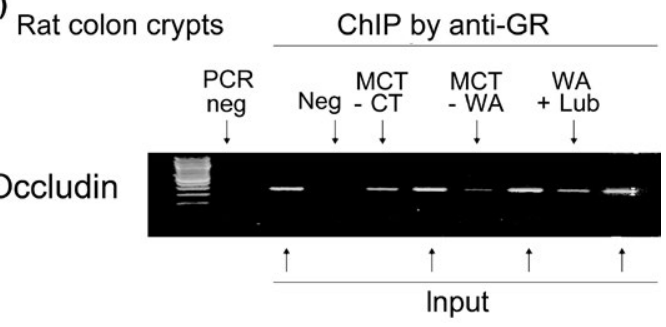

(B) Caco-2/BBE

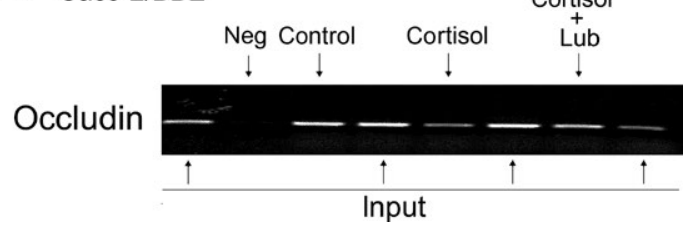

FIGURE 7 Chromatin immunoprecipitation (ChIP) followed by PCR analysis for transcription factor GR binding to occludin promoter regions in rat colon crypts and differentiated Caco-2/ BBE cells. A, ChIP using anti-GR antibody followed by PCR for occludin promoter in colon crypts isolated from MCT-CT, MCT-WA, WA+Lub rats. PCR neg: no input DNA; ChIP neg: ChIP with normal rabbit lgG. Input: $4 \%$ input DNA from relevant rat crypt samples for normalization. B, ChIP and PCR analysis of GR binding to occludin promoter region in differentiated Caco-2/BBE cells treated by cortisol $(500 \mathrm{nmol} / \mathrm{L})$ for 24 hours in the presence and absence of lubiprostone (100 $\mathrm{nmol} / \mathrm{L})$

reported that claudin-2 is increased in the jejunum in IBS with diarrhea, ${ }^{46}$ supporting an important role of this tight junction protein in regulation of intestinal barrier function.

In our previous study, we observed significant decrease in GR receptor expression in colon epithelial cells in the stressed and corticosterone-treated rats, which was largely blocked by corticoid receptor antagonist RU-486. ${ }^{9}$ In this study, we further demonstrated that GR protein was down-regulated in differentiated Caco-2/BBE cells and normal human colon crypts after cortisol treatment that was associated with increased paracellular permeability, suggesting a role for GR in modulation of tight junction protein expression and function. These results are consistent with other studies using in vitro cell lines. ${ }^{47,48}$ Our ChIP-qPCR analysis showed that GR could directly bind to occludin promoter and this GR binding was decreased in the colon crypts in WA-stressed rats, indicating a direct regulatory role of $\mathrm{GR}$, as a positive transcription factor, for occludin transcription and expression. Restoration of GR protein by lubiprostone thus reserved the decrease in GR transcriptional binding to occludin promoter induced by chronic stress, increased occludin transcription and expression, and subsequently normalized paracellular permeability. Similar regulatory role of GR for claudin-1 was reported in our recent study. ${ }^{34}$ Interestingly, chronic stress-induced decrease in GR expression was prevented by lubiprostone in Caco-2/BBE cells and human colon crypts, but not in chronic WA stress rat model which showed a modest effect. One possible explanation is the complexity of in vivo rat stress model compared to the relatively simple in vitro model using cultured cells/crypts. Adrenocorticotropic hormone, at systemic level, and several neuropeptides, at local level, can be
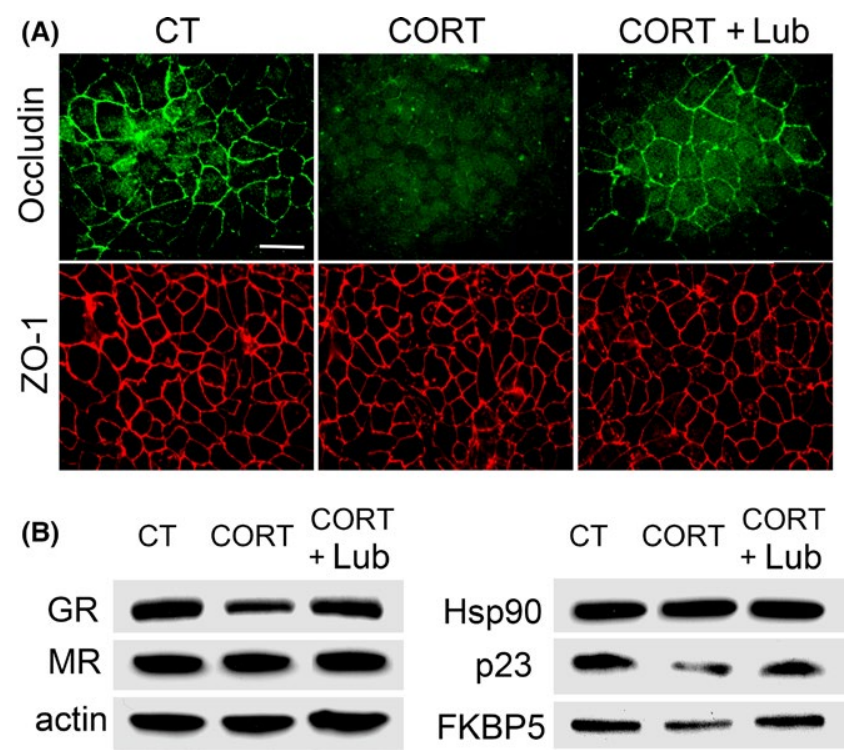

FIGURE 8 Effects of corticosterone (CORT) and lubiprostone on occludin, GR, and GR chaperone proteins in rat colonic FRC/ TEX cells. A, Immunofluorescence for occludin and ZO-1 expression in $\mathrm{FRC} / \mathrm{TEX}$ cells treated by corticosterone $(500 \mathrm{nmol} / \mathrm{L})$ for 24 hours in the presence and absence of lubiprostone (100 nmol/L). The expression and localization of occludin but not ZO-1 was significantly disrupted in corticosterone-treated cells compared to the controls. Lubiprostone largely reversed this change. B, Immunoblots for GR, MR, and GR chaperone proteins Hsp90, p23, and FKBP5 in $500 \mathrm{nmol} / \mathrm{L}$ corticosterone-treated FRC/TEX cells for 24 hours with/without lubiprostone (100 nmol/L). $\mathrm{n}=3$

released in the animal model under chronic stress conditions, which may modulate GR transcriptional binding to occludin and claudin-1 promoter regions in the presence of lubiprostone. Secondly, we observed large variability in down-regulation of GR protein in stressed rats and in stressed rats treated with lubiprostone. The difference in baseline levels of GR receptor, tight junction proteins, and their epigenetic regulatory status in healthy control rats, including DNA methylation in gene promoter regions, may contribute to the differential effects observed in animals subjected to chronic stress and lubiprostone treatment. Further studies are needed to dissect the detailed regulatory pathways in stress axis that are involved in regulation of differential restoration of disrupted epithelial tight junction proteins by lubiprostone.

Like many signaling proteins, the function of GR depends on the coordination of $\mathrm{Hsp} 90$ and $\mathrm{Hsp} 70$ chaperone cycles. Full recovery of ligand binding to GR requires ATP hydrolysis on $\mathrm{Hsp} 90$ and the Hop and p23 co-chaperones. ${ }^{15}$ In our study, both Hsp90 and Hsp70 were not affected by GR agonist, cortisol/corticosterone, in Caco-2/BBE and FRC/TEX cells. However, p23 expression was significantly down-regulated in the colon epithelial cells in stressed rats and colonic cell lines treated with glucocorticoids, suggesting the recovery of GR ligand binding was significantly incapacitated under chronic stress conditions. In addition, FKBP5, a Hsp90 cochaperone that regulates GR function, ${ }^{49}$ was decreased in glucocorticoid-treated colonic cells. This result is consistent with the 
previous report that FKBP5 links to the development of posttraumatic stress disorder (PTSD) and was found to be less expressed in PTSD. ${ }^{50}$ These data strongly support a function of FKBP5 as a modulator of the response to stressful life events. It is very likely that FKBP5 functions in chronic stress through its action in GR resistance and translocation. ${ }^{17}$ Accordingly, down-regulation of GR altered the transcription and expression of epithelial tight junction proteins and disrupted barrier function under chronic stress conditions and subsequently induced visceral hyperalgesia in stressed animals. However, the exact mechanism underlying how these co-chaperones modulate GR ligand binding and translocation to the nucleus in colon epithelial cells in chronic stress remains to be elucidated.

It has been reported that lubiprostone significantly improves symptoms in patients with chronic constipation ${ }^{51}$ and is more effective than placebo in improving abdominal pain or bloating in IBS patients with constipation. ${ }^{52}$ The signal transduction pathway includes activation of $\mathrm{CIC}-2$ channels resulting in a chloride-rich fluid secretion, activation of prostaglandin $\mathrm{E}$ type receptors with increase in mucus/fluid secretion, and restitution of epithelial cell barrier properties. ${ }^{26,28,51}$ The current study demonstrates that lubiprostone significantly reduced chronic stress-induced visceral hyperalgesia in the rat, which is consistent with the effects reported in IBS patients. ${ }^{52}$ This beneficial effect of lubiprostone most likely contributes to the prevention of chronic stress-induced changes in epithelial tight junction proteins including claudin-1, claudin-2, and occludin, and subsequent recovery of paracellular permeability in both in vivo and in vitro models. Importantly, our study further demonstrated a novel role for lubiprostone to regulate epithelial barrier function through modulation of GR expression and function. Lubiprostone significantly prevented down-regulated of GR co-chaperones including p23 and FKBP5 induced by chronic stress, suggesting a signaling modulation through GR ligand binding recovery and nucleus translocation. The prevention of down-regulation in $G R$ results in reconstitution of $G R$ binding to tight junction gene promoter regions and increases epithelial cell tight junction gene transcription, protein expression, and thereby restores epithelial cell barrier integrity and function. On the other hand, heat-shock proteins have been reported to regulate chloride channel expression and function. ${ }^{53}$ Recovery of p23 and FKBP5 by lubiprostone may, therefore, lead to enhancement of chloride channel activity and fluid secretion to reduce chronic stress-induced symptoms. In our study, we cannot exclude the possibility that lubiprostone may also directly activate CIC-2 chloride channels ${ }^{25,54}$ since lubiprostone was gavage-delivered in rat models and administrated in the inner chamber of transwell cultures of Caco-2 cells. However, the fact that lubiprostone does not affect fecal pellet output in stressed rats does not support the involvement of direct activation of CIC-2 channels in this animal model. It is noteworthy that GR co-chaperone p23 is also identified as prostaglandin E synthase 3, a cytosolic prostaglandin E2 synthase. The recovery of the expression and function of this prostaglandin $\mathrm{E}$ synthase may increase the production of prostaglandin E2, activate prostaglandin EP receptors, and downstream signaling pathways that promote intestinal epithelial restoration. ${ }^{55}$

In summary, our results support the novel concept that lubiprostone has a protective role in chronic stress-induced impairment in intestinal epithelial cell tight junction protein expression and function resulting in visceral hyperalgesia. These actions of lubiprostone appear to be attributable to the prevention of stress-induced disruption of intestinal epithelial tight junction protein expression and maintenance of intestinal barrier function associated with modulation of GR receptor expression and function. GR, acting as a positive transcription factor for claudin-1 and occludin, regulates tight junction gene transcription and expression. Chronic stress-induced downregulation of GR receptor, therefore, leads to GR-mediated decreases in tight junction proteins claudin-1 and occludin and increase in claudin-2, resulting in increased paracellular permeability in animal models and cell lines. Lubiprostone treatment significantly prevents stress-induced down-regulation of GR receptor and its chaperone proteins, which promotes the recovery of GR-mediated regulation of tight junction protein expression, paracellular permeability, and visceral pain perception. These observations may help guide future drug development in this area by providing a rationale to target pathways that either prevent impairment and/or promote restoration in intestinal epithelial cell tight junction protein expression and function.

\section{ACKNOWLEDGMENTS}

This study was supported by grants R01 DK098205 to JWW and R21 AT009253 to JWW and SH from the National Institutes of Health, by Takeda Pharmaceutical Co., Ltd., and by Pilot/Feasibility grant to SH from the University of Michigan Center for Gastrointestinal Research (NIH grant P30 DK34933).

\section{CONFLICT OF INTERESTS}

The authors have no competing interests.

\section{AUTHOR CONTRIBUTIONS}

Ye Zong and Shuangsong Hong planned and designed the study; Shutian Zhang and John W Wiley provided assistance for experiment planning and data interpretation; Ye Zong, Shengtao Zhu, and Gen Zheng conducted experiments; Ye Zong and Shuangsong Hong analyzed the data and wrote and revised the article, and all authors contributed to review of the manuscript.

\section{ORCID}

Shuangsong Hong (iD http://orcid.org/0000-0003-2488-8764 


\section{REFERENCES}

1. Lovell RM, Ford AC. Global prevalence of and risk factors for irritable bowel syndrome: a meta-analysis. Clin Gastroenterol Hepatol. 2012;10(7):712-721.e4.

2. Aziz I, Tornblom H, Palsson OS, et al. How the change in IBS criteria from Rome III to Rome IV impacts on clinical characteristics and key pathophysiological factors. Am J Gastroenterol. 2018;113:1017-1025.

3. Lacy BE, Rome P. Criteria and a Diagnostic Approach to Irritable Bowel Syndrome. J Clin Med. 2017;6(11):E99.

4. Vivinus-Nebot M, Dainese R, Anty R, et al. Combination of allergic factors can worsen diarrheic irritable bowel syndrome: role of barrier defects and mast cells. Am J Gastroenterol. 2012;107:75-81.

5. Zhou Q, Zhang B, Verne GN. Intestinal membrane permeability and hypersensitivity in the irritable bowel syndrome. Pain. 2009;146:41-46.

6. Piche T, Barbara G, Aubert P, et al. Impaired intestinal barrier integrity in the colon of patients with irritable bowel syndrome: involvement of soluble mediators. Gut. 2009;58:196-201.

7. Chang L. The role of stress on physiologic responses and clinical symptoms in irritable bowel syndrome. Gastroenterology. 2011;140:761-765.

8. Kelly JR, Kennedy PJ, Cryan JF, et al. Breaking down the barriers: the gut microbiome, intestinal permeability and stress-related psychiatric disorders. Front Cell Neurosci. 2015;9:392.

9. Zheng G, Wu SP, Hu Y, et al. Corticosterone mediates stress-related increased intestinal permeability in a region-specific manner. Neurogastroenterol Motil. 2013;25:e127-e139.

10. Xu D, Gao J, Gillilland M III, et al. Rifaximin alters intestinal bacteria and prevents stress-induced gut inflammation and visceral hyperalgesia in rats. Gastroenterology. 2014;146(2):484-496.e4.

11. Langhorst J, Junge A, Rueffer A, et al. Elevated human beta-defensin-2 levels indicate an activation of the innate immune system in patients with irritable bowel syndrome. Am J Gastroenterol. 2009;104:404-410.

12. Dunlop SP, Hebden J, Campbell E, et al. Abnormal intestinal permeability in subgroups of diarrhea-predominant irritable bowel syndromes. Am J Gastroenterol. 2006;101:1288-1294.

13. Wiley JW, Higgins GA, Athey BD. Stress and glucocorticoid receptor transcriptional programming in time and space: Implications for the brain-gut axis. Neurogastroenterol Motil. 2016;28:12-25.

14. Cattaneo A, Riva MA. Stress-induced mechanisms in mental illness: A role for glucocorticoid signalling. J Steroid Biochem Mol Biol. 2015;160:169-174.

15. Kirschke E, Goswami D, Southworth D, et al. Glucocorticoid receptor function regulated by coordinated action of the Hsp90 and Hsp70 chaperone cycles. Cell. 2014;157:1685-1697.

16. Pratt WB, Morishima Y, Murphy M, et al. Chaperoning of glucocorticoid receptors. Handb Exp Pharmacol. 2006;172:111-138.

17. Binder EB. The role of FKBP5, a co-chaperone of the glucocorticoid receptor in the pathogenesis and therapy of affective and anxiety disorders. Psychoneuroendocrinology. 2009;34(Suppl 1):S186-S195

18. Grad I, Picard D. The glucocorticoid responses are shaped by molecular chaperones. Mol Cell Endocrinol. 2007;275:2-12.

19. Blair LJ, Sabbagh JJ, Dickey CA. Targeting Hsp90 and its co-chaperones to treat Alzheimer's disease. Expert Opin Ther Targets. 2014;18:1219-1232.

20. Liu TS, Musch MW, Sugi K, et al. Protective role of HSP72 against Clostridium difficile toxin A-induced intestinal epithelial cell dysfunction. Am J Physiol Cell Physiol. 2003;284:C1073-C1082.

21. Matsuo $\mathrm{K}$, Zhang $\mathrm{X}$, Ono $\mathrm{Y}$, et al. Acute stress-induced coIonic tissue HSP70 expression requires commensal bacterial components and intrinsic glucocorticoid. Brain Behav Immun 2009;23:108-115.

22. Bao HF, Liu L, Self J, et al. A synthetic prostone activates apical chloride channels in A6 epithelial cells. Am J Physiol Gastrointest Liver Physiol. 2008;295:G234-G251.

23. Lacy BE, Chey WD. Lubiprostone: chronic constipation and irritable bowel syndrome with constipation. Expert Opin Pharmacother. 2009:10:143-152.

24. Simren M, Tack J. New treatments and therapeutic targets for IBS and other functional bowel disorders. Nat Rev Gastroenterol Hepatol. 2018; https://doi.org/10.1038/s41575-018-0034-5.

25. Nighot PK, Blikslager AT. Chloride channel CIC-2 modulates tight junction barrier function via intracellular trafficking of occludin. Am J Physiol Cell Physiol. 2012;302:C178-C187.

26. Moeser AJ, Nighot PK, Engelke KJ, et al. Recovery of mucosal barrier function in ischemic porcine ileum and colon is stimulated by a novel agonist of the $\mathrm{ClC}-2$ chloride channel, lubiprostone. Am J Physiol Gastrointest Liver Physiol. 2007;292:G647-G656.

27. Hong S, Fan J, Kemmerer ES, et al. Reciprocal changes in vanilloid (TRPV1) and endocannabinoid (CB1) receptors contribute to visceral hyperalgesia in the water avoidance stressed rat. Gut. 2009:58:202-210.

28. Hayashi S, Kurata N, Yamaguchi A, et al. Lubiprostone prevents nonsteroidal anti-inflammatory drug-induced small intestinal damage by suppressing the expression of inflammatory mediators via EP4 receptors. J Pharmacol Exp Ther. 2014;349:470-479.

29. Hong S, Zheng G, Wiley JW. Epigenetic regulation of genes that modulate chronic stress-induced visceral pain in the peripheral nervous system. Gastroenterology. 2015;148(1):148-157.e7.

30. Ferruzza S, Rossi C, Scarino ML, et al. A protocol for differentiation of human intestinal Caco-2 cells in asymmetric serum-containing medium. Toxicol In Vitro. 2012;26:1252-1255.

31. Pories SE, Weber TK, Simpson H, et al. Immortalization and neoplastic transformation of normal rat colon epithelium: an in vitro model of colonic neoplastic progression. Gastroenterology. 1993;104:1346-1355.

32. Cha MC, Lin A, Meckling KA. Low dose docosahexaenoic acid protects normal colonic epithelial cells from araC toxicity. BMC Pharmacol. 2005;5:7.

33. Dame MK, Jiang Y, Appelman HD, et al. Human colonic crypts in culture: segregation of immunochemical markers in normal versus adenoma-derived. Lab Invest. 2014;94:222-234.

34. Zheng G, Victor Fon G, Meixner W, et al. Chronic stress and intestinal barrier dysfunction: Glucocorticoid receptor and transcription repressor HES1 regulate tight junction protein Claudin-1 promoter. Sci Rep. 2017;7:4502.

35. Hong $\mathrm{S}$, Zheng $\mathrm{G}, \mathrm{Wu} \mathrm{X}$, et al. Corticosterone mediates reciprocal changes in CB 1 and TRPV1 receptors in primary sensory neurons in the chronically stressed rat. Gastroenterology. 2011;140:627-637.

36. Overgaard CE, Daugherty BL, Mitchell LA, et al. Claudins: control of barrier function and regulation in response to oxidant stress. Antioxid Redox Signal. 2011;15:1179-1193.

37. Jin $\mathrm{Y}$, Blikslager AT. CIC-2 regulation of intestinal barrier function: Translation of basic science to therapeutic target. Tissue Barriers. 2015;3:e1105906.

38. Oliveira SS, Morgado-Diaz JA. Claudins: multifunctional players in epithelial tight junctions and their role in cancer. Cell Mol Life Sci. 2007;64:17-28.

39. Inai T, Kobayashi J, Shibata Y. Claudin-1 contributes to the epithelial barrier function in MDCK cells. Eur J Cell Biol. 1999;78:849-855.

40. Gunzel D, Fromm M. Claudins and other tight junction proteins. Compr Physiol. 2012;2:1819-1852.

41. Furuse M, Furuse K, Sasaki H, et al. Conversion of zonulae occludentes from tight to leaky strand type by introducing claudin-2 into Madin-Darby canine kidney I cells. J Cell Biol. 2001;153:263-272. 
42. Wilmes A, Aschauer L, Limonciel A, et al. Evidence for a role of claudin 2 as a proximal tubular stress responsive paracellular water channel. Toxicol Appl Pharmacol. 2014;279:163-172.

43. Rosenthal R, Gunzel D, Theune D, et al. Water channels and barriers formed by claudins. Ann N Y Acad Sci. 2017;1397:100-109.

44. Chandrasekharan B, Jeppsson S, Pienkowski S, et al. Tumor necrosis factor-neuropeptide $Y$ cross talk regulates inflammation, epithelial barrier functions, and colonic motility. Inflamm Bowel Dis. 2013;19:2535-2546.

45. Ahmad R, Kumar B, Pan K, et al. HDAC-4 regulates claudin-2 expression in EGFR-ERK1/2 dependent manner to regulate colonic epithelial cell differentiation. Oncotarget. 2017;8:87718-87736.

46. Martinez C, Rodino-Janeiro BK, Lobo B, et al. miR-16 and miR-125b are involved in barrier function dysregulation through the modulation of claudin-2 and cingulin expression in the jejunum in IBS with diarrhoea. Gut. 2017;66:1537-1538.

47. Kelly SP, Chasiotis H. Glucocorticoid and mineralocorticoid receptors regulate paracellular permeability in a primary cultured gill epithelium. J Exp Biol. 2011;214:2308-2318.

48. Felinski EA, Cox AE, Phillips BE, et al. Glucocorticoids induce transactivation of tight junction genes occludin and claudin-5 in retinal endothelial cells via a novel cis-element. Exp Eye Res. 2008;86:867-878.

49. Wochnik GM, Ruegg J, Abel GA, et al. FK506-binding proteins 51 and 52 differentially regulate dynein interaction and nuclear translocation of the glucocorticoid receptor in mammalian cells. J Biol Chem. 2005;280:4609-4616.

50. Yehuda R, Cai G, Golier JA, et al. Gene expression patterns associated with posttraumatic stress disorder following exposure to the World Trade Center attacks. Biol Psychiatry. 2009;66:708-711.
51. Johanson JF, Morton D, Geenen J, et al. Multicenter, 4-week, double-blind, randomized, placebo-controlled trial of lubiprostone, a locally-acting type- 2 chloride channel activator, in patients with chronic constipation. Am J Gastroenterol. 2008;103:170-177.

52. Chang L, Chey WD, Drossman D, et al. Effects of baseline abdominal pain and bloating on response to lubiprostone in patients with irritable bowel syndrome with constipation. Aliment Pharmacol Ther. 2016;44:1114-1122.

53. Peng YJ, Huang JJ, Wu HH, et al. Regulation of CLC-1 chloride channel biosynthesis by FKBP8 and Hsp90beta. Sci Rep. 2016;6:32444.

54. Cuppoletti J, Blikslager AT, Chakrabarti J, et al. Contrasting effects of linaclotide and lubiprostone on restitution of epithelial cell barrier properties and cellular homeostasis after exposure to cell stressors. BMC Pharmacol. 2012;12:3.

55. Miyoshi H, VanDussen KL, Malvin NP, et al. Prostaglandin E2 promotes intestinal repair through an adaptive cellular response of the epithelium. EMBO J. 2017;36:5-24.

How to cite this article: Zong Y, Zhu S, Zhang S, Zheng G, Wiley JW, Hong S. Chronic stress and intestinal permeability: Lubiprostone regulates glucocorticoid receptor-mediated changes in colon epithelial tight junction proteins, barrier function, and visceral pain in the rodent and human. Neurogastroenterol Motil. 2019;31:e13477. https://doi. org/10.1111/nmo.13477 